03

\title{
Оптические спектры кристаллов GaSe и GaS различной толщины
}

\author{
(C) В.Ф. Агекян, А.Ю. Серов, Н.Г. Философров \\ Санкт-Петербургский государственный университет, \\ Санкт-Петербург, Россия \\ E-mail: v.agekyan@spbu.ru
}

(Поступила в Редакцию 18 декабря 2017 г.)

Исследованы спектры пропускания кристаллов $\mathrm{GaSe}$ и $\mathrm{GaS}$ различной толщины, полученные методом механического расслаивания объемных кристаллов. В тонких образцах GaSe квантово-размерные сдвиги экситонных резонансов достигают $12 \mathrm{meV}$, что близко к величине энергии связи экситона. Высокоэнергетические межзонные переходы в $\mathrm{GaSe}$ и $\mathrm{GaS}$ наблюдаются около 3.4 и $3.7 \mathrm{eV}$ соответственно.

DOI: 10.21883/FTT.2018.06.46002.348

В последнее время активно ведутся экспериментальные и теоретические исследования зонной структуры и экситонных состояний в ультратонких, вплоть до одного атомного слоя, кристаллах. В этом отношении привлекательны кристаллы, отдельные слои которых связаны друг с другом лишь силами Ван-дер-Вальса и слабыми кулоновскими силами. Популярными объектами такого типа являются кристаллы группы III-VI [1-7], обладающие сильными нелинейными оптическими свойствами, в частности, в таких кристаллах низок порог генерации гармоник $[8,9]$. Отсутствие валентных связей между слоями позволяет создавать ненапряженные гетероструктуры с высоким качеством интерфейсов даже при сильном различии постоянных решетки по обе стороны от интерфейса, это показано на примере структуры с квантовыми ямами InSe/GaSe [10].

В настоящей работе исследовались спектры пропускания кристаллов селенида и сульфида галлия различной толщины. В этих кристаллах валентные связи замкнуты внутри слоя, состоящего из четырех атомных плоскостей $\mathrm{VI}-\mathrm{Ga}-\mathrm{Ga}-\mathrm{VI}$ (тетрапакет - TP). В зависимости от взаимного расположения слоев образуются различные политипы с гексагональной или ромбоэдрической симметрией решетки. Объемные кристаллы $\mathrm{GaSe}$ обычно являются смесью $\gamma$ и $\varepsilon$ модификаций, у которых ширина запрещенной зоны различается лишь на несколько meV. GaS имеет лишь $\beta$ модификацию. В GaSe энергии прямого и непрямого межзонных переходов практически совпадают, в $\mathrm{GaS}$ прямой переход находится выше непрямого на $0.2 \mathrm{eV}$.

Развитие методов получения кристаллов с малым числом элементарных слоев является актуальной задачей. Формирование однородных по толщине кристаллов селенида и сульфида галлия с большими латеральными размерами часто встречает затруднения вследствие слабого взаимодействия между слоевыми пакетами. На плоских подложках обычно растут сложные нерегулярные структуры дендритного типа [11]. В случае применения лазерного расслаивания объемных кристал- лов образуются нанотрубки и структуры в форме луковиц [12]. Одним из методов является расслаивание кристаллов, помещенных в жидкость, с помощью ультразвука с последующим перемещением тонких кристаллов на твердую подложку [13]. В случае применения таких технологий объектом исследования является образец, состоящий из набора кристаллов с различными толщинами и латеральными размерами, что затрудняет интерпретацию оптических спектров.

В настоящей работе тонкие кристаллы $\mathrm{GaSe}$ и $\mathrm{GaS}$ были изготовлены с помощью механического расслаивания объемных кристаллов, выращенных методом Бриджмена. О высоком качестве этих кристаллов свидетельствует спектр люминесценции, где наблюдается лишь полоса излучения экситона (рис. 1). Был получен набор образцов, каждый из которых имеет большие латеральные размеры и одинаковую толщину по всей площади. В спектрах пропускания этих образцов (рис. 2, 3) наблюдается регулярная система интерференционных полос.

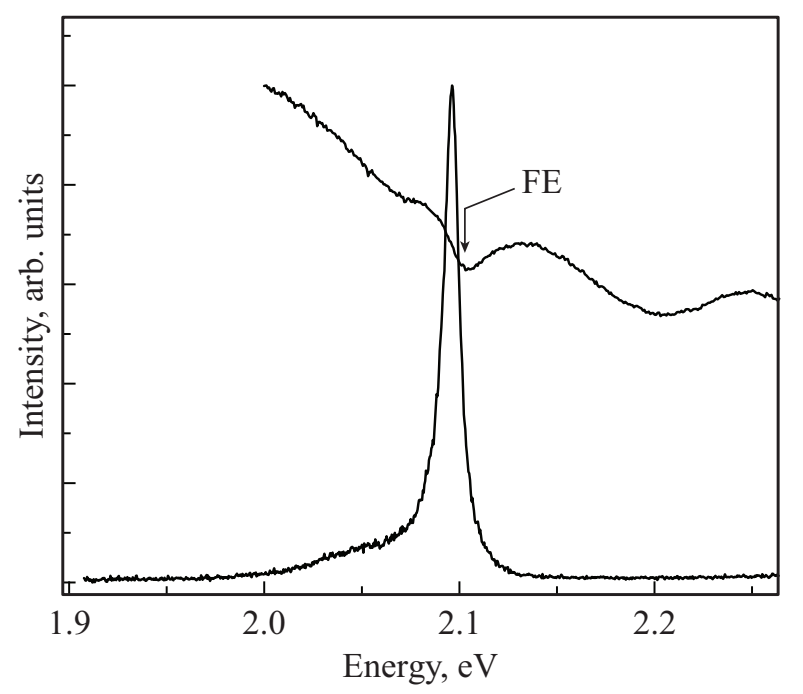

Рис. 1. Спектры пропускания и люминесценции $\mathrm{GaSe}, \mathrm{FE}-$ полоса основного состояния экситона. $T=80 \mathrm{~K}$. 
Интерференционная картина усложняется в образцах, на поверхности которых образовались ступени, в самых тонких образцах интерференция не наблюдается (верхний спектр на рис. 2).

Рассмотрим основное состояние экситона, энергия которого в объемном кристалле селенида галлия равна $2.10 \mathrm{eV}$ при $T=80 \mathrm{~K}$ [14]. На рис. 4 представлены спектры пропускания кристаллов селенида галлия в

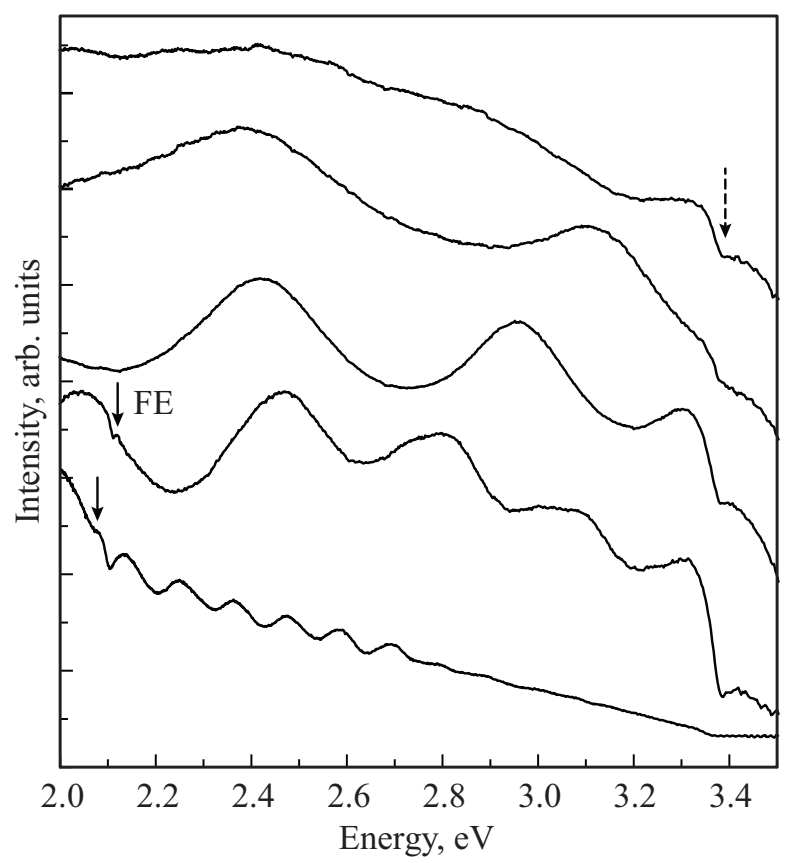

Pис. 2. Спектры пропускания кристаллов GaSe различной толщины; сплошными стрелками показан экситонный резонанс FE первого межзонного перехода, штриховой стрелкой обозначен высокоэнергетический межзонный переход. $T=80 \mathrm{~K}$.

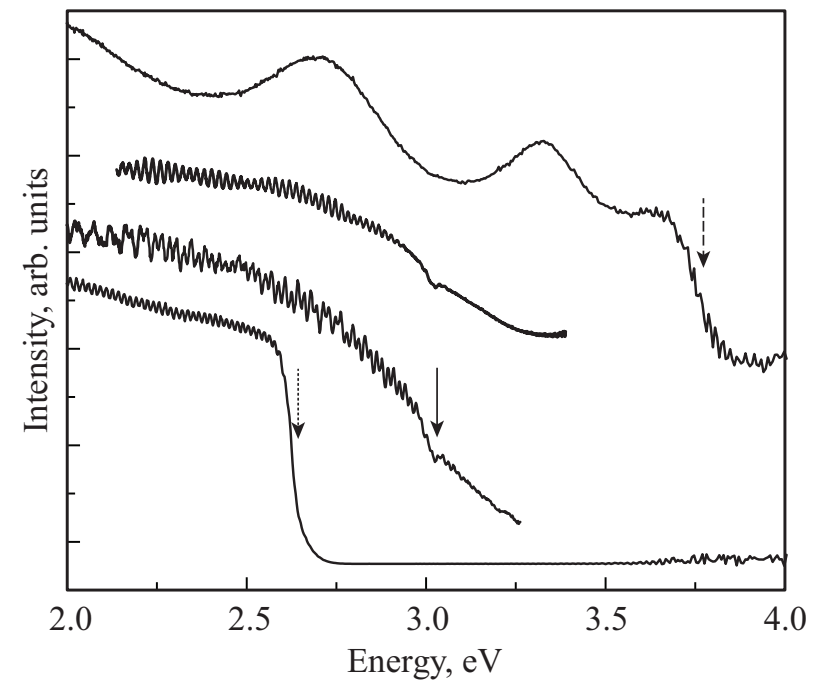

Рис. 3. Спектры пропускания кристаллов $\mathrm{GaS}$ различной толщины. Пунктирная стрелка - непрямой межзонный переход, сплошная стрелка - экситон первого прямого перехода, штриховая стрелка - высокоэнергетический прямой межзонный переход. $T=80 \mathrm{~K}$.

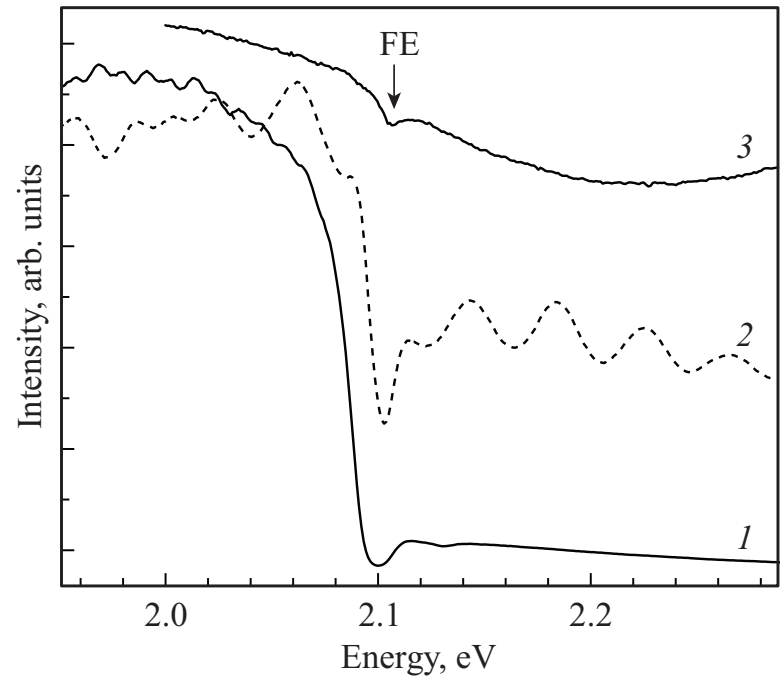

Pис. 4. Спектры пропускания кристаллов $\mathrm{GaSe}$ в области основного состояния экситона FE. Толщина образцов уменьшается от 1 к $3 . T=80 \mathrm{~K}$.

области прямого перехода. В самом тонком кристалле квантово-размерный сдвиг линии основного состояния экситона равен $12 \mathrm{meV}$. Энергия связи экситона в $\mathrm{GaSe}$ равна $20 \mathrm{meV}$, то есть мы имеем случай промежуточный между слабым и сильным конфайнментами, когда толщина кристалла и размер экситона близки по величине. В направлении, перпендикулярном слоям, значения диэлектрической проницаемости и приведенной эффективной массы носителей в GaSe равны 7.6 и $0.14 m_{0}$, что соответствует экситонному радиусу около $3 \mathrm{~nm}$. Постоянная решетки $\mathrm{GaSe}$ в направлении перпендикулярном слоям составляет $2.4 \mathrm{~nm}$ ( $\gamma$ модификация) и $1.6 \mathrm{~nm}$ ( $\varepsilon$ модификация). Можно сделать вывод, что толщина нашего самого тонкого кристалла равна нескольким ТР $\mathrm{Se}-\mathrm{Ga}-\mathrm{Ga}-\mathrm{Se}$.

В работе [13] особенности в области $3 \mathrm{eV}$ в спектре пропускания селенида галлия отнесены к основному экситонному состоянию кристалла толщиной в один ТР, которое смещено в сторону высоких энергий на $1 \mathrm{eV}$ относительно энергии экситона в объемном GaSe. По нашему мнению, это утверждение недостаточно обосновано, поскольку спектр пропускания, приведенный в работе [13], получен не от одного кристалла определенной толщины, а от набора кристаллов, имеющих разные толщины. Отметим, что в спектре пропускания кристаллов селенида галлия с различными толщинами, в области выше $3 \mathrm{eV}$ наблюдаются особенности, относящиеся к высокоэнергетическому межзонному переходу (отмечены стрелками на рис. 2).

В кристалле $\mathrm{GaS}$ ( $\beta$ модификация) расстояние между слоями существенно меньше, чем в $\gamma$ модификации, и валентные связи внутри $\mathrm{TP} \mathrm{S}-\mathrm{Ga}-\mathrm{Ga}-\mathrm{S}$ значительно сильнее, чем в $\mathrm{TP} \mathrm{Se}-\mathrm{Ga}-\mathrm{Ga}-\mathrm{Se}$. Методом механического расслаивания не удалось получить кристаллы $\mathrm{GaS}$ столь же тонкие, как GaSe. В спектрах пропуска- 
ния кристаллов сульфида галлия различной толщины, приведенных на рис. 3, наблюдаются непрямой переход, экситонный резонанс прямого перехода и высокоэнергетический межзонный переход около $3.7 \mathrm{eV}$.

Итак, методом механического расслаивания получены ультратонкие кристаллы группы III-VI, в которых величина квантово-размерного сдвига основного состояния экситона близка к величине его энергии связи в объемном кристалле. Высокоэнергетические межзонные переходы в $\mathrm{GaSe}$ и $\mathrm{GaS}$ находятся около 3.4 и $3.7 \mathrm{eV}$ соответственно.

\section{Список литературы}

[1] S.L. Stoll, E.G. Gillan, A.R. Barron. Chem. Vapor Deposition 2, 182 (1996).

[2] V. Chikan, D.F. Kelley. Nano Lett. 2, 141 (2002).

[3] A. Keys, S.G. Bott, A.R. Barron. Chem. Mater. 11, 3578 (1999).

[4] H. Peng, S. Meister, C.K. Chan, X.F. Zhang, Y. Cui. Nano Lett. 7, 199 (2007).

[5] V. Zolyomi, N.D. Drummond, V.I. Fal'ko. Phys. Rev. B 87, 195403 (2013).

[6] C.J. Zhang, X. Liu, V. Nicolosi. Bioenergetics 5, 221 (2016).

[7] J. Shao, H. Mirafzal, J.R. Petker, J.L.S. Cosio, D.F. Kelley, T. Ye. J. Phys. Chem. C 113, 19102 (2009).

[8] J.M. Auerhammer, E.R. Eliel. Opt. Lett. 21, 773 (1996).

[9] L. Kador, D. Haarer. Appl. Phys. Lett. 69, 731 (1996).

[10] O. Lang, A. Klein, C. Pettenkofer, W. Jaegermann, A. Chevy. J. Appl. Phys. 80, 3817 (1996).

[11] E. Ertap, T. Baydar, Yuksek, M. Karabulut. Turk. J. Phys. 40, 297 (2016).

[12] U.K. Gautam, S.R.C. Vivekchand, A. Govindaraj, G.U. Kulkarni, N.R. Selvi, C.N.R. Rao. J. Am. Chem. Soc. 127, 3658 (2005).

[13] D.V. Rybkovskiy, N.R. Arutyunyan, A.S. Orekhov, I.A. Gromchenko, I.V. Vorobiev, A.V. Osadchy, E.Yu. Salaev, T.K. Baykara, K.R. Allakhverdiev, E.D. Obraztsova. Phys. Rev B 84, 085314 (2011).

[14] Г.Л. Беленький, В.Б. Стопачинский. УФН 140, 254 (1983). 